\title{
Iniciação Científica dos Cursos de Engenharia da Universidade de Pernambuco.
}

Title: Scientific Initiation in Engineering Courses of the University of Pernambuco.

\author{
Betânia da Mata Ribeiro Gomes \\ Universidade de Pernambuco \\ 50.720-001 - Recife, Brasil \\ betania.mata@upe.br
}

\author{
Diego José Rativa Millan \\ Universidade de Pernambuco \\ 50.720-001 - Recife, Brasil \\ diego.rativa@ecomp.poli.br
}

\author{
Sergio Campello Oliveira \\ Universidade de Pernambuco \\ 50.720-001 - Recife, Brasil \\ scampello@ecomp.poli.br
}

\begin{abstract}
A Universidade de Pernambuco (UPE) é uma universidade pública estadual multicampi e vem se desenvolvendo bastante desde sua fundação como universidade há 25 anos. Anualmente, a UPE promove a Semana Universitária com diversas atividades ocorrendo em todas as suas unidades.
\end{abstract}

\begin{abstract}
A Semana Universitária da UPE possibilita aos estudantes de iniciação científica, aos participantes de projetos de extensão e de ensino, assim como aos estudantes de pós-graduação, apresentarem os trabalhos desenvolvidos ao longo do ano num evento integrado que reúne toda a comunidade acadêmica da UPE bem como de outras instituições de ensino e pesquisa da região. Apenas no ano de 2015, um número total de 457 trabalhos, dos quais 232 de Iniciação Científica, foram apresentados durante o evento. As apresentações destes trabalhos são divididas em módulos temáticos, de acordo com as áreas do CNPq, são avaliados por uma comissão composta por três professores especialistas na área de concentração do trabalho e os melhores trabalhos em cada área de conhecimento são premiados.
\end{abstract}

Os Programas de Iniciação Científica estão entre os mais exitosos dentre as linhas de financiamento da pesquisa brasileira. O Programa Institucional de Bolsas de Iniciação Cientifica (PIBIC) possibilita maior envolvimento dos estudantes de graduação em atividades de pesquisa, bem como sua maior participação nos Grupos de Pesquisa e no apoio a PósGraduação, fortalecendo os Programas stricto sensu. A Iniciação Científica (IC) apresenta ao aluno o cenário real em que as pesquisas científicas são realizadas, desmistificando o ato de se produzir ciência, ao mesmo tempo em que introduz o acadêmico num ambiente em que é estimulada a troca de informações e o livre questionamento do conhecimento.

Esta edição especial da Revista de Engenharia e Pesquisa Aplicada (REPA) publica os trabalhos de Iniciação Científica desenvolvidos na Escola Politécnica de Pernambuco nos anos de 2009 a 2015. Esses trabalhos fortalecem substancialmente os sete cursos de Graduação em Engenharia, os quatro programas de Mestrado e as diversas especializações pertencentes à Escola Politécnica da Universidade de Pernambuco, ou apenas POLI.

Os trabalhos aqui publicados, foram avaliados por bancas examinadoras mediante apresentações orais durante as semanas universitárias, porem os manuscritos não foram submetidos a um processo de avaliação normal de uma revista, por essa razão estão recompilados como uma edição especial da REPA. Os artigos estão organizados cronologicamente por seções anuais desde o ano de 2009 até 2015 e por seções por área de estudo. Não poderíamos deixar de agradecer a César José Santana da Silva pelo seu trabalho cuidadoso na edição deste volume. 
É com imensa satisfação que levamos ao público geral, através deste importante veículo de divulgação, a Revista de Engenharia e Pesquisa Aplicada, uma mostra da ciência produzida por nossos alunos de Iniciação Científica.

Cordialmente,
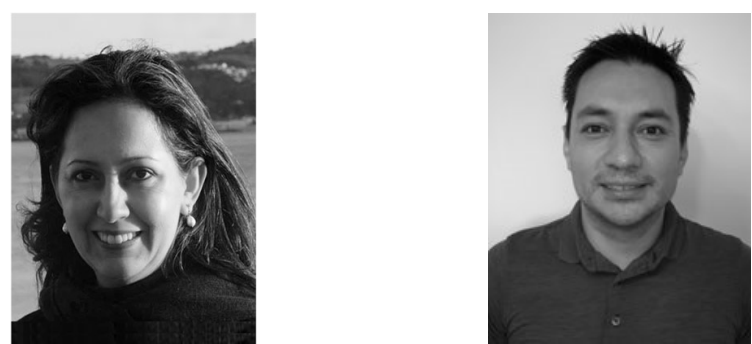

Betânia da Mata Ribeiro Gomes, graduada em Enfermagem (1990), mestre em Hebiatria (2007) pela Universidade de Pernambuco doutora em Ciências pela Universidade de São Paulo (2012). Atualmente é Professora Adjunto do Curso de Enfermagem, é membro do Mestrado em Enfermagem e Coordenadora Geral de Pesquisa da Universidade de Pernambuco.
Diego Rativa, doutor em Engenharia Elétrica pela Universidade Federal de Pernambuco (2008), atuou como pesquisador pós-doutoral da Science Foundation Ireland e da Entreprise Ireland (2008-2011), e neste momento é professor adjunto e coordenador do curso de Engenharia da Computação da Universidade de Pernambuco, é membro permanente do Mestrado em Engenharia de Sistemas e Gerente da Divisão de Pesquisa da Escola Politécnica de Pernambuco.

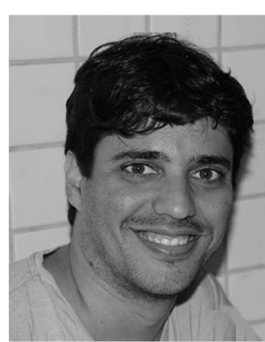

Sérgio Campello Oliveira, graduado, mestre e doutor em Engenharia Eletrônica pela Universidade Federal de Pernambuco (2001, 2004 e 2008). Atualmente é Professor Associado da Universidade de Pernambuco. Atuou como coordenador de graduação, Gerente de departamento e Gerente de Pesquisa na Escola Politécnica de Pernambuco. Atualmente é membro permanente do Mestrado em Engenharia de Sistemas e coordenador Geral de Pós-Graduação da Universidade de Pernambuco. 